\section{Hasty energy review risks failing to win public trust}

SIR — The UK government recently announced the launch of its second energy review in three years. Many have commented on the substantive issues and technologies; we wish to draw attention to the limitations of the review process itself. Our concerns draw on three decades of study of the governance of science and technology, and we recognize that, although the review encompasses complex issues involving high stakes and disputed values, it supports a limited degree of public engagement.

Three months have been allocated for decisions that may have implications for thousands of years. Although there is urgency to this issue, and legislative timetables create potential time constraints, the length of the decision-making process should be determined by the scope and complexity of the problem, and the public should be given sufficient notice and resources to respond meaningfully.

An authoritative and legitimate process must be open to a range of possible outcomes, but there is a widespread perception that the government has made its mind up in favour of nudear energy. If the consultation is to have integrity and to generate trust, the task of initiating the review should be separated from the tasks of convening and implementing it. Furthermore, good review processes must have the authority that comes from participants knowing in advance that their inputs will be taken seriously, and the initiators should be explicit about how the review's findings will be used in future decision-making processes.

The explicit context of such an enquiry, or 'framing' as social scientists call it, is itself contentious. Some may question whether framing the energy-review process in terms of climate-change obligations or the security of gas supplies is appropriate. If a process is to be recognized as legitimate, it must engage participants in the task of choosing the appropriate framing. Scenario approaches like those used by the Intergovernmental Panel on Climate Change to think about alternative policies can produce a manageable number of distinct, internally consistent and plausible alternatives.

Critics of earlier consultation efforts have focused on whether the methods used were representative. We argue that there is no single correct method: there is strength in using an array of tools to address different aspects of the problem and to allow diverse forms of input. We would also urge the government to recognize that non-specialist forms of knowledge, based on people's everyday experiences, can provide a valuable complement to officially recognized expertise. Without substantive public engagement, the government risks reinforcing the mistrust, controversy and technological failure that we have seen all too often in recent years. James Tansey

James Martin Institute for Science and Civilization, Said Business School, Park End Street,

Oxford OX11HP, UK

Other signotories of this let ter.

David Gee Europeon Enwronment Agency

Melissaleachinstitute of Development Studies, University of Sussex

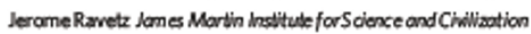

Alister Scott The Knowledge Avidge, Eost Sussex

Andrew Stiling Soience and Technology Palligy Research,

University of Sussex

Bronislaw Sxe rszyndi Centre for the Study of Envionmental Ohange,

Lancoster University

Tam Wakeford Palig, Ehics and Life Soiences Reseorch Centre,

University of Newcostle upon Tyne

\section{Silence isn't necessarily an admission of guilt}

SIR - The reaction of C. R. McMahon and colleagues (Nature 439,$392 ; 2006$ ) to your News story "Animal-rights group sues over 'disturbing' work on sea lions" (Nature 436, 315 ;2005) - pointing out that much animal handling, such as seal branding, is a necessary prerequisite to effective conservation - is exceptional, because it represents a rare instance of a voiced scientific opinion on a sensitive topic.

Scientists themselves are often 'branded' by the media, but are ill-equipped to defend themselves, having neither the time nor the schooling in this area. Alternatively, they may fear intimidation or be obliged not to enter the fray by governing bodies.

Of the various groups involved in animalrights issues, those taking an accusatory stance would do well to consider that silence is not always an admission of guilt.

Rory P. Wilson

Institute of Environmental Sustainability, School of the Enviranment and Society, University of Wales Swansea, Singleton Park, Swansea SA2 8PP, UK

\section{GOOS can help to keep an eagle eye on the oceans}

SIR - Your Editorial "Circulation challenge" (Nature 439, 244; 2006) calls for ocean observations to be "sustained for much longer periods than foreseen in the six-year RAPID programme" and "augmented globally". But you do not mention the Global Ocean Observing System (GOOS; see ioc.unesco. org/goos), which already exists specifically to take up this challenge.

GOOS provides an operational structure for sustained global observations comprising the oceanographic component of the Global
Earth Observing System of Systems. The open-ocean module of GOOS is designed to describe and forecast the state of the physical ocean in order to help understand and predict weather and climate. Its implementation is achieved by pooling the commitments of individual nations, made through their government agencies, navies and oceanographic research institutions, together with sponsorship from international agencies.

Not long ago, Nature called for enhanced support for GOOS ("Making sense of the

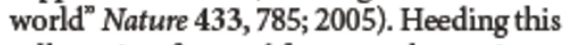
call requires first and foremost that nations support the development of a robust commitments mechanism that can efficiently take stock of national efforts and at the same time increase the resources available for coordination. GOOS will also need to increase its efforts to reach, and cater for, a wider range of contributors and users of the system. GOOS welcomes the circulation challenge.

Keith Alverson

GOOS Project Office, 10C/UNESCO,

1 rue Miollis, 75732 Paris, Cedex 15, France

\section{Giants of physics found white-dwarf mass limits}

SIR - In his Essay "The death of a star" (Nature 438, 1086; 2005) Freeman Dyson pays a well-deserved tribute to astrophysicist Subrahmanyan Chandrasekhar's lifetime of work. Your readers may be interested to know that Wilhelm Anderson of Tartu University in Estonia and Edmund Stoner of the University of Leeds in England separately published white-dwarf mass limits that predated what has come to be known as the "Chandrasekhar limit' (S. Chandrasekhar Astrophys. J. 74, 81-82; 1931).

Anderson (Z. Phys. 1, 851-856; 1929) made the fundamental conceptual coupling of relativity and quantum statistical mechanics that leads to a mass limit. And Stoner (Philos. Mag. 9, 944-963; 1930) produced a robust calculation from first principles and calculated the mass limit for a uniform-density star. The Stoner and Chandrasekhar mass limits differ by $20 \%$, owing to their use of different stellar-density models. But this difference is small, given that the presence of any mass limit at all was the key breakthrough.

Eric Blackman

Department of Physics and Astronamy, University of Rochester, Rochester, New York 14627, USA

Contributions to Correspondence may be submitted to corres@nature.com. They should be no longer than $\mathbf{5 0 0}$ words, andideally shorter. Published contributions are edited. 